\title{
Fontes de minerais orgânicos e inorgânicos para leitões desmamados
}

\author{
Organic and inorganic mineral sources for weanling piglets
}

\section{Mendelson Henrique Baldassa Muniz ${ }^{I}$ Dirlei Antonio Berto ${ }^{\mathrm{I}}$ Regina Maria Nascimento Augusto ${ }^{\mathrm{I} *}$ Messias Alves Trindade Neto ${ }^{\mathrm{II}}$ Francisco Stefano Wechsler $^{\mathrm{I}}$ Vivian Lo Tierzo ${ }^{\mathrm{I}}$ Lucélia Hauptli $^{\mathrm{I}}$}

\section{RESUMO}

\begin{abstract}
A presente pesquisa foi realizada com o objetivo de comparar os efeitos de fontes orgânicas e inorgânicas de microminerais sobre o desempenho, os parâmetros sanguíneos e a deposição de minerais em tecidos e órgãos de leitões desmamados. Foram utilizados 54 leitões de genética comercial, desmamados com idade média de 24 dias e peso

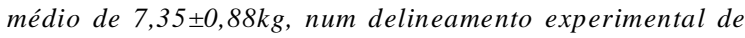
blocos ao acaso, com dois tratamentos, nove repetições e três animais por parcela. Os tratamentos foram representados pelo uso de rações suplementadas com minerais de fontes orgânicas ou inorgânicas ( $\mathrm{Cu}, \mathrm{Zn}, \mathrm{Fe}, \mathrm{Mn}$ e Se) no período dos 24 aos 57 dias de idade. Foram avaliados o consumo diário de ração, o ganho diário de peso, a conversão alimentar, os parâmetros hematológicos e a deposição de minerais em tecidos e órgãos. As fontes orgânicas de minerais nas rações fornecidas dos 24 aos 57 dias de idade melhoraram o ganho diário de peso $(P=0,06)$ e a conversão alimentar $(P=0,05)$ e aumentaram $o$ número de hemáceas $(P=0,10)$, contudo não influenciaram a deposição de minerais no músculo masseter, fígado, coração, baço e rim. Portanto, o suplemento de minerais de fontes orgânicas foi mais eficiente para o desempenho dos leitões na fase de creche.
\end{abstract}

Palavras-chave: micromineral, mineral quelatado, suínos.

\section{ABSTRACT}

This research was conducted in order to compare the effects of organic and inorganic sources of mineral sources on performance, blood parameters and deposition of minerals in tissues and organs of nursery piglets. This experiment used 54 piglets from a commercial line, which were weaned at the mean age of 24 days and mean weight of $7.35 \pm 0,88 \mathrm{~kg}$, in a randomized block design with two treatments, nine replicates and three animals per replicate. The treatments consisted of rations supplemented with either organic or inorganic mineral sources ( $\mathrm{Cu}, \mathrm{Zn}, \mathrm{Fe}, \mathrm{Mn}$ and Se) during the 24 to 57 days old. It was evaluated daily feed intake, daily weight gain, gain ratio, hematological parameters, mineral deposition in tissues and organs. The organic mineral sources fed from 24 to 57 days of age improved daily weight gain $(P=0.06)$ and feed: gain ratio $(P=0.05)$ and also raised red blood cell count $(P=0.10)$; however, no effect was found on mineral deposition in the masseter muscle, liver, heart, spleen or kidneys. Therefore, organics minerals sources increased performance of nursery piglets.

Key words: chelated mineral, micro-mineral, swine.

\section{INTRODUÇÃO}

A evolução das técnicas de criação tem possibilitado melhores desempenhos produtivo e reprodutivo dos suínos, permitindo aos nutricionistas formularem dietas cada vez mais específicas, de modo a atender, com maior precisão, as exigências dos animais. Por outro lado, as variações na biodisponibilidade de minerais, as ações de sinergismo ou antagonismo existentes entre minerais e os problemas ambientais cada vez mais crescentes com o uso de fontes inorgânicas nas rações de suínos têm alertado pesquisadores a buscarem alternativas que resultem em menor excreção pelos animais.

'Departamento de Produção e Exploração Animal, Faculdade de Medicina Veterinária e Zootecnia (FMVZ), Universidade Estadual Paulista (UNESP), 18618-970, Botucatu, SP, Brasil. E-mail: reginamaria.uel@gmail.com. *Autor para correspondência.

"Departamento de Nutrição e Produção Animal, Faculdade de Medicina Veterinária e Zootecnia, Universidade de São Paulo (USP), Pirassununga, SP, Brasil. 
A formulação de dietas com níveis de microminerais $(\mathrm{Cu}, \mathrm{Zn}, \mathrm{Fe}, \mathrm{Mn}$ e Se) que excedem as recomendações nutricionais (NRC, 1998; ROSTAGNO et al. 2005) tem sido muito utilizada nas granjas de suínos. $\mathrm{O}$ excesso empregado, entretanto, acarreta maior excreção desses elementos devido ao mecanismo homeostático dos tecidos. A adoção dessa estratégia é uma das alternativas importantes para reduzir o impacto ambiental provocado pela produção suinícola, pois visa a minimizar a suplementação e maximizar a eficiência de utilização dos nutrientes (MURPHY \& LANGE, 2004).

O objetivo deste trabalho foi comparar os efeitos de fontes orgânicas e inorgânicas de microminerais $(\mathrm{Cu}, \mathrm{Zn}, \mathrm{Fe}, \mathrm{Mn}$ e $\mathrm{Se})$ sobre o desempenho, os parâmetros sanguíneos e a deposição de minerais em tecidos e órgãos de leitões desmamados.

\section{MATERIAL E MÉTODOS}

O experimento foi realizado na Universidade Estadual Paulista, nas instalações de creche do Setor de Suinocultura da Faculdade de Medicina Veterinária e Zootecnia, campus de Botucatu. Foram usados 54 leitões, sendo machos castrados e fêmeas com alto potencial genético, desmamados com idade média de 24 dias e peso de 7,35 $\pm 0,88 \mathrm{~kg}$. Os animais foram alojados em salas de creche, contendo baias suspensas com piso ripado medindo $1,00 \times 1,75 \mathrm{~m}$ (três animais/baia), equipadas com bebedouro tipo chupeta, comedouro e campânula para aquecimento.

O delineamento experimental foi o de blocos ao acaso, com dois tratamentos, nove repetições e três animais por parcela. Os critérios para a formação dos blocos foram pesos, sexo e leitegada. Os tratamentos avaliados foram rações com suplementação de fontes inorgânicas ou orgânicas de microminerais quelatados ( $\mathrm{Cu}, \mathrm{Zn}, \mathrm{Fe}, \mathrm{Mn}$ e Se), elaborados com níveis de garantia para atender, no mínimo, às recomendações nutricionais propostas pelo NRC (1998) para leitões desmamados, com os seguintes níveis de suplementação $\left(\mathrm{mg} \mathrm{kg}^{-1} \mathrm{de}\right.$ ração): $\mathrm{Zn}$ - 80,0; Cu - 5,0; Mn - 20,0; Se - 0,25; Fe - 80,0. $\mathrm{O}$ iodo $(0,14)$ foi fornecido na forma de iodato de cálcio em ambos os suplementos, na concentração de $0,14 \mathrm{mg}$ $\mathrm{kg}^{-1}$ de ração.

Adotou-se o programa de alimentação de acordo com as seguintes fases: ração pré-inicial ( 0 ao

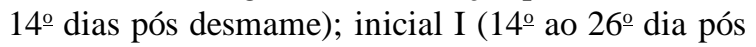
desmame) e inicial II (26ㅇa ao 33ㅇ dia pós desmame) (Tabela 1). As dietas foram formuladas para atender as exigências nutricionais propostas pelo NRC (1998) para cada uma das fases estudadas, sendo fornecidas à vontade. Foram avaliados o consumo diário de ração, o ganho diário de peso e a conversão alimentar nos períodos compreendidos entre 0-14, 0-26 e 0-33 dias pós-desmame.

Após a última pesagem, foram coletadas amostras de sangue de cada animal para avaliação da porcentagem de hematócrito $(\mathrm{Ht})$, determinada pelo método do microhematócrito, segundo GOLDENFARB et al. (1971), e contagem do número de eritrócitos e leucócitos, realizadas pelo método do hematocitômetro em câmara de Neubauer, utilizando como diluente a solução azul de toluidina a $0,01 \%$ em pipeta de Thoma. A taxa de hemoglobina (hb) foi determinada pelo método da cianometahemoglobina utilizando-se o kit comercial Analisa Dignóstica ${ }^{\circledR}$, para determinação colorimétrica, segundo COLLIER (1994). A contagem de plaquetas foi realizada segundo metodologia proposta por COLES (1984)

Nove animais de cada tratamento foram abatidos após terem sido definidos, por sorteio, em cada um dos blocos (um por baia), para avaliação das concentrações de Fe, Mn, Zn e Cu no fígado, coração, baço, rim e músculo (masseter). As concentrações de microminerais nos tecidos e órgãos foram determinadas pela técnica de espectrometria de absorção atômica com chama, sendo utilizado aparelho VARIAN - Atomic Absorption Spectrophotometer.

Os dados de desempenho e os dados hematológicos foram submetidos à análise de variância (ANOVA), com o auxílio do procedimento GLM do programa SAS (1998), sendo as médias comparadas pelo teste F. Os resultados referentes à concentração de minerais foram analisados por meio do procedimento MIXED do SAS (2003), após prévia transformação logarítmica. O modelo incluiu os efeitos fixos do tratamento, do tecido e da interação tratamento $\mathrm{x}$ tecido e os efeitos aleatórios de bloco, interação bloco x tratamento e resíduo. As médias estimadas e seus errospadrão foram revertidos à escala original.

\section{RESULTADOS E DISCUSSÃO}

Os resultados de consumo diário de ração, ganho diário de peso e conversão alimentar dos leitões são apresentados na tabela 2 . Nos períodos de 24 a 38 e de 24 a 50 dias de idade, os resultados de desempenho não diferiram com o uso das fontes orgânicas ou inorgânicas de minerais. No período acumulado de 24 a 57 dias de idade, o ganho diário de peso $(\mathrm{P}=0,06)$ e a conversão alimentar $(\mathrm{P}=0,05)$ foram melhores para os animais alimentados com rações contendo minerais de fontes orgânicas, evidenciando uma tendência demonstrada nos períodos de 24 a 38 dias e de 24 a 50 dias de idade. 
Tabela 1 - Composição percentual e nutricional das rações fornecidas aos leitões durante a fase de creche.

\begin{tabular}{|c|c|c|c|}
\hline Ingredientes (\%) & $\begin{array}{l}\text { Pré-inicial } \\
\text { (24- } 38 \text { dias) }\end{array}$ & $\begin{array}{c}\text { Inicial I } \\
\text { (39-50 dias) }\end{array}$ & $\begin{array}{c}\text { Inicial II } \\
\text { (51-57dias) }\end{array}$ \\
\hline Milho & 51,300 & 61,320 & 67,450 \\
\hline Farelo de soja & 27,000 & 28,680 & 27,210 \\
\hline Soja extrusada & 4,320 & 0,250 & 0,000 \\
\hline Soro leite & 8,180 & 4,110 & 0,000 \\
\hline Farinha de peixe & 3,000 & 0,000 & 0,000 \\
\hline Células sanguíneas & 0,450 & 0,090 & 0,330 \\
\hline Levedura seca & 0,750 & 0,630 & 0,450 \\
\hline Açúcar & 1,460 & 0,850 & 0,000 \\
\hline Calcário & 1,230 & 1,110 & 1,610 \\
\hline Fosfato bicálcico & 0,910 & 1,410 & 1,350 \\
\hline Edulcorante $^{1}$ & 0,015 & 0,015 & 0,015 \\
\hline BHT & 0,015 & 0,015 & 0,015 \\
\hline Sal & 0,280 & 0,430 & 0,570 \\
\hline L-lisina- $\mathrm{HCl}$ & 0,150 & 0,190 & 0,130 \\
\hline DL-metionina & 0,050 & 0,050 & 0,040 \\
\hline L-treonina & 0,070 & 0,050 & 0,030 \\
\hline L-triptofano & 0,020 & 0,000 & 0,000 \\
\hline Suplemento mineral ${ }^{2}$ & 0,500 & 0,500 & 0,500 \\
\hline Suplemento vitamínico ${ }^{3}$ & 0,300 & 0,300 & 0,300 \\
\hline Total & 100,00 & 100,00 & 100,00 \\
\hline \multicolumn{4}{|l|}{ Valores calculados } \\
\hline Energia metabolizável $\left(\mathrm{kcal} \mathrm{kg}^{-1}\right)$ & 3291 & 3252 & 3166 \\
\hline Proteína bruta (\%) & 21,82 & 18,78 & 18,93 \\
\hline Lisina total $(\%)$ & 1,39 & 1,15 & 1,11 \\
\hline Metionina total $(\%)$ & 0,39 & 0,32 & 0,31 \\
\hline Treonina total $(\%)$ & 0,92 & 0,76 & 0,74 \\
\hline Triptofano total (\%) & 0,27 & 0,22 & 0,22 \\
\hline Cálcio (\%) & 0,99 & 0,82 & 0,72 \\
\hline Fósforo disponível (\%) & 0,43 & 0,37 & 0,35 \\
\hline
\end{tabular}

${ }^{1}$ Sucran, produto comercial da Metachen. ${ }^{2}$ Suplemento contendo fontes orgânicas (minerais quelatados) ou inorgânicas de microminerais, suprindo as seguintes quantidades $\mathrm{kg}^{-1}$ de ração: $5 \mathrm{mg}$ de cobre; $80 \mathrm{mg}$ de zinco; $80 \mathrm{mg}$ de ferro; $20 \mathrm{mg}$ de manganês; $0,25 \mathrm{mg}$ de selênio e $0,14 \mathrm{mg}$ de I. ${ }^{3}$ Suplemento vitamínico suprindo as seguintes quantidades $\mathrm{kg}^{-1}$ de ração: $6.000 \mathrm{UI}$ vit. A; $1.320 \mathrm{UI}$ vit D3; $12 \mathrm{mg}$ vit. E; $1,47 \mathrm{mg}$ vit. K3; 0,9mg vit. B1; 3mg vit. B2; 1,8mg vit. B6; 12 mcg vit. B12; 0,3mg ác. fólico; 9,3mg ác. pantotênico; 18mg niacina; 0,09mg biotina; 240mg de colina.

Vários trabalhos foram realizados para comparar fontes inorgânicas e orgânicas de um único mineral em níveis nutricionais para suínos, especialmente zinco (CHENG et al., 1998; REVY et al., 2002; HEUGTEN et al., 2003), manganês (KATS et al., 1994) e selênio (MAHAN \& KIN, 1996; MAHAN et al., 1999), não demonstrando diferenças nos parâmetros de desempenho dos animais, condição distinta do presente experimento, que, com exceção do iodo, apresentou os demais microminerais nos suplementos oriundos de fontes orgânicas ou inorgânicas. Contudo, CREECHet al. (2004), ao compararem uma dieta controle com níveis normais de minerais inorgânicos $(\mathrm{Zn}, \mathrm{Cu}$, $\mathrm{Fe}, \mathrm{Mn}, \mathrm{Se}$ ) e dietas com minerais orgânicos ou quelatados em quantidades reduzidas, não encontraram diferenças significativas no desempenho dos animais, nas fases de creche e de crescimento.

A comparação de fontes inorgânicas de cobre $\left(\mathrm{CuSO}_{4}\right)$ e $\mathrm{Zn}\left(\mathrm{ZnSO}_{4}\right)$ com fontes orgânicas (cobre e zinco complexo aminoácido e cobre e zinco quelato-aminoácido), em rações de leitões, foi realizada por LEE et al. (2001). No entanto, estes não verificaram diferenças significativas no consumo de ração e ganho de peso, no período compreendido entre 24 e 38 dias de idade; entretanto, a conversão alimentar apresentou-se melhor nos animais que receberam $170 \mathrm{ppm}$ de cobre e 120ppm de zinco nas formas de quelatos ou complexos. No período total do experimento, os leitões alimentados com rações contendo 170ppm de cobre e $120 \mathrm{ppm}$ de zinco como 
Tabela 2 - Valores médios de consumo diário de ração (CDR), ganho diário de peso (GDP) e conversão alimentar (CA) de leitões alimentados com rações contendo microminerais de fontes orgânicas ou inorgânicas nos períodos de 24 a 38, 24 a 50 e 24 a 57 dias de idade.

\begin{tabular}{|c|c|c|c|c|c|}
\hline \multirow[b]{2}{*}{ Idade, dias } & \multirow[b]{2}{*}{ Variável } & --------_- & 1-------------- & \multirow[b]{2}{*}{ E. P. ${ }^{1}$} & \multirow[b]{2}{*}{$\mathrm{P}$} \\
\hline & & Orgânica & Inorgânica & & \\
\hline \multirow{3}{*}{$24-38$} & CDR (g) & 485 & 485 & 9 & 0,10 \\
\hline & GDP $(\mathrm{g})$ & 363 & 351 & 5 & 0,10 \\
\hline & $\mathrm{CA}$ & 1,36 & 1,38 & 0,02 & 0,10 \\
\hline \multirow{3}{*}{$24-50$} & CDR (g) & 747 & 734 & 14 & 0,10 \\
\hline & GDP (g) & 461 & 444 & 10 & 0,10 \\
\hline & $\mathrm{CA}$ & 1,62 & 1,68 & 0,02 & 0,10 \\
\hline \multirow{3}{*}{$24-57$} & CDR (g) & 871 & 845 & 17 & 0,10 \\
\hline & GDP (g) & 503 & 474 & 10 & 0,06 \\
\hline & $\mathrm{CA}$ & 1,73 & 1,79 & 0,01 & 0,05 \\
\hline
\end{tabular}

${ }^{1}$ Erro-padrão da média.

quelato ou complexo aminoácido ou 85 e 60ppm de cobre e de zinco, como complexo aminoácido, apresentaram melhor conversão alimentar.

As diferenças significativas no ganho de peso e na conversão alimentar evidenciam que a combinação de fontes orgânicas de microminerais promove melhores condições para o desenvolvimento dos leitões. De acordo com CREECH et al. (2004), a absorção dos minerais quelatados, $\mathrm{Cu}, \mathrm{Zn}$, Fe e Mn, é maior nos animais em fase de creche.

Os resultados dos parâmetros sanguíneos dos leitões são apresentados na tabela 3. Animais suplementados com fontes orgânicas e inorgânicas de minerais não apresentaram diferença no número de eritrócitos $(\mathrm{P}=0,10)$, discordando dos resultados obtidos por CREECH et al. (2004), os quais observaram que animais tratados com minerais orgânicos apresentaram maior concentração de hemoglobina. Independentemente da fonte mineral utilizada, os valores dos parâmetros sanguíneos encontraram-se dentro da faixa de normalidade para a categoria, segundo os valores obtidos por FELDMAN et al. (2000).

As concentrações de minerais verificadas no tecido muscular e nos órgãos dos leitões são apresentadas na tabela 4 . Não houve efeito $(\mathrm{P}=0,10)$ das fontes de microminerais sobre esses parâmetros. Os teores de ferro e zinco no fígado, cobre e zinco no coração e zinco no baço e rim foram próximos aos determinados por LUO \& DOVE (1996), quando forneceram dietas para leitões com $15 \mathrm{mg}$ de $\mathrm{Cu}, 150 \mathrm{mg}$ de Fe, 200mg de Zn, 10mg de Mn, 0,15mg de I e 0,3mg de Se por quilo de ração. Valores maiores de deposição de cobre no fígado e baço e de ferro no fígado de leitões após o desmame foram verificados por BERTO et al. (1997). Entretanto, o suplemento usado garantia níveis superiores de cobre (80ppm) e de ferro (300ppm) na ração.

Ao compararem duas fontes de zinco sob diferentes níveis na ração de leitões desmamados, REVY et al. (2002) verificaram que a concentração plasmática

Tabela 3 - Parâmetros sanguíneos de leitões alimentados com rações contendo microminerais de fontes orgânicas ou inorgânicas.

\begin{tabular}{|c|c|c|c|c|}
\hline \multirow[b]{2}{*}{ Parâmetros } & \multicolumn{2}{|c|}{ 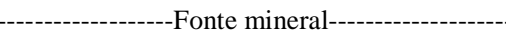 } & \multirow[b]{2}{*}{$\mathrm{EEP}^{1}$} & \multirow[b]{2}{*}{$\mathrm{P}$} \\
\hline & Orgânica & Inorgânica & & \\
\hline Hematócrito (\%) & 36,91 & 36,00 & 0,54 & 0,10 \\
\hline 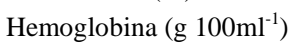 & 11,60 & 11,40 & 0,16 & 0,10 \\
\hline Eritrócitos $\left(10^{6} \mathrm{~mm}^{-3}\right)$ & 6,70 & 6,51 & 0,07 & 0,10 \\
\hline Leucócitos $\left(10^{3} \mathrm{~mm}^{-3}\right)$ & 13,24 & 13,21 & 0,82 & 0,10 \\
\hline Plaquetas $\left(10^{3} \mathrm{~mm}^{-3}\right)$ & 395,82 & 381,64 & 28,35 & 0,10 \\
\hline
\end{tabular}

\footnotetext{
${ }^{1}$ Erro-padrão das médias.
} 
Tabela 4 - Concentrações de minerais no fígado, coração, baço, rim e músculo (masseter) de leitões contendo microminerais de fontes orgânicas ou inorgânicas nas rações de leitões em fase de creche.

\begin{tabular}{|c|c|c|c|c|c|}
\hline \multirow{2}{*}{ Tecidos/órgãos } & \multirow{2}{*}{ Fonte mineral } & Ferro & Manganês & Zinco & Cobre \\
\hline & & \multicolumn{4}{|c|}{---------------------------------------(ppm) ------------------------------------- } \\
\hline \multirow{2}{*}{ Fígado } & Orgânico & 214,22 & 6,44 & 68,44 & 7,00 \\
\hline & Inorgânico & 252,00 & 6,44 & 71,11 & 7,22 \\
\hline \multirow{2}{*}{ Coração } & Orgânico & 83,11 & 3,33 & 18,22 & 2,89 \\
\hline & Inorgânico & 90,67 & 2,89 & 18,22 & 3,00 \\
\hline \multirow{2}{*}{ Baço } & Orgânico & 323,56 & 3,33 & 25,11 & 1,22 \\
\hline & Inorgânico & 405,33 & 4,00 & 26,89 & 1,11 \\
\hline \multirow{2}{*}{ Rim } & Orgânico & 99,56 & 4,22 & 31,78 & 10,89 \\
\hline & Inorgânico & 114,67 & 4,89 & 32,22 & 11,44 \\
\hline \multirow{2}{*}{ Masseter } & Orgânico & 44,89 & 3,56 & 23,78 & 1,44 \\
\hline & Inorgânico & 46,67 & 3,33 & 23,56 & 1,22 \\
\hline $\mathrm{EP}^{1}$ & & 1,09 & 1,13 & 1,05 & 1,13 \\
\hline
\end{tabular}

${ }^{1}$ Erro-padrão das médias.

do mineral elevou-se com o aumento da inclusão. A deposição no osso e no fígado foi maior somente quando o mineral foi incluído em níveis de 20 ou 30ppm, e a fonte não influenciou a concentração de zinco nos tecidos.

O aumento nos teores de zinco no metacarpo e nas vértebras coccígeas de suínos também foi relatado por WEDEKIND et al. (1994), com a suplementação dietética de zinco ( $\mathrm{ZnSO})$ até 45 a 50ppm, níveis menores que o nível usado ño presente experimento. Por outrolado, CASE \& CARLSON (2002) observaram aumento nos teores de zinco no fígado e nos rins de suínos alimentados com rações contendo 3000ppm de zinco como óxido de zinco, porém isso não ocorreu com a adição de 500ppm.

\section{CONCLUSÃO}

O suplemento de minerais de fontes orgânicas foi mais eficiente para leitões na fase de creche, com reflexos positivos nos parâmetros de desempenho, sem alterar a taxa de deposição de minerais nos tecidos e órgãos.

\section{REFERÊNCIAS}

BERTO, A.B. et al. Efeitos da adição de cobre e zinco nas rações sobre a deposição de minerais no fígado, baço e rins de leitões. In: REUNIÃO NACIONAL DA SOCIEDADE BRASILEIRA DE ZOOTECNIA, 34., 1997, Juiz de Fora. Anais... Juiz de Fora: SBZ, 1997. p.75-77.

CASE, C.L.; CARLSON, M.S. Effect of feeding organic and inorganic sources of additional zinc on growth performance and zinc balance in nursery pigs. Journal of Animal Science, v.80, n.7, p.1917-1924, 2002. Disponível em: <http:// jas.fass.org/cgi/content/full/80/7/1917>. Acesso em: 13 maio, 2007.

CHENG, J. et al. Influence of dietary lysine on the utilization of zinc form zinc sulphate and zinc-lysine complex by young pigs. Journal of Animal Science, v.76, p.1064-1074, 1998. Disponível em: <http://jas.fass.org>. Acesso em: 05 nov. 2006.

COLES, E.H. Patologia clínica veterinária. 3.ed. São Paulo: Manole, 1984. 1p.

COLLIER, H.B. The standardization of blood haemoglobin determinations. Canadian Medical Association Journal, v.50, p.550-552, 1994. Disponível em: <http:// www.ncbi.nlm.nih.gov/pmc/articles/PMC1581573/pdf/ canmedaj00573-0133.pdf>. Acesso em: 15 mar. 2007.

CREECH, B.L. et al. Effect of dietary trace mineral concentration and source (inorganic vs. chelated) on performance, mineral status, and fecal mineral excretion in pigs from weaning through finishing. Journal of Animal Science, v.82, p.2140-2147, 2004. Disponível em: <http:// jas.fass.org>. Acesso em: 19 jan. 2007.

FELDMAN, B.F. et al. Schalman's veterinary hematology, 5.ed. Local: editora, 2000. 1p.

GOLDENFARB, P.B. et al. Reproducibility in the hematology laboratory: the microhematócrito determination. American Journal of Clinical Pathology, v.56, p.35-39, 1971. Disponível em: <http://www.ncbi.nlm.nih.gov/pubmed/ 5556212>. Acesso em: 10 maio, 2007.

HEUGTEN, E. et al. Effects of organic forms of zinc on growth performance, tissue zinc distribution, and immune response of weanling pigs. Journal of Animal Science, v.81, p.2063-2071, 2003. Disponível em: <http://jas.fass.org/cgi/ content/full/81/8/2063>. Acesso em: 21 jan. 2007.

KATS, L.J. et al. Effect of chelated manganese on growth performance and carcass of finishing pigs. Kansas Swine 
Day, v.165, p.165-167, 1994. Disponível em: <http://krex.kstate.edu/dspace/bitstream/2097/3337/1/Swine94pg165167.pdf>. Acesso em: 03 dez. 2006.

LEE, S.H. et al. Evaluation of metal-amino acid chelates and complexes at various levels of copper and zinc in weanling pigs and broiler chicks. Asian-Australian Journal of Animal Science, v.14, n.12, p.1734-1740, 2001. Disponível em: < h t t p ://grande.nal.usda.gov/ibids / index.php?mode2=detail\&origin=ibids_references\&therow=492147>. Acesso em: 25 abr. 2007.

LUO, G.X.; DOVE, C.R. Effect of dietary copper and fat on nutrient utilization, digestive enzyme activies, and tissue mineral levels in weanling pigs. Journal of Animal Science, v.74, p.1888-1896, 1996. Disponível em: <http://jas.fass.org/cgi/ reprint/74/8/1888>. Acesso em: 11 fev. 2007.

MAHAN, D.C.; KIM, Y.Y. Effect of inorganic or organic selenium at two dietary levels on reproductive performance and tissue selenium concentration in first-parity gilts and their progeny. Journal of Animal Science, v.76, p.2711-2718, 1996. Disponível em: <http://jas.fass.org/cgi/reprint/74/11/ 2711>. Acesso em: 25 mar. 2007.

MAHAN, D.C. et al. Effects of dietary levels of seleniumenriched yeast and sodium selenite as sources fed to growingfinishing pigs on performance, tissue selenium, serum glutathine peroxidase activity, carcass characteristics, and loin quality. Journal of Animal Science, v.77, p.2172-2179, 1999. Disponível em: <http://jas.fass.org/cgi/reprint/77/8/2172>. Acesso em: 15 mar. 2007.
MURPHY, J.; LANGE, L. Nutritional Strategies to minimize nutrient output. In: LONDON SWINE CONFERENCE BUILDING BLOCKS FOR THE FUTURE, 9., 2004, Ontario. Proceedings... Ontario: London Swine Conference, 2004. p.5771, 1-2. Disponível em: <http://www.londonswineconference.ca/ proceedings/2004/2004>. Acesso em: 02 fev. 2007.

NATIONAL RESEARCH COUNCIL - NRC. Nutrient requirement of swine. 10.ed. Washington: National Academic, 1998. p.189.

REVY, P.S. et al. Bioavailability of two sources of zinc in weanling pigs. Animal Research, v.51, p.315-326, 2002. Disponível em: <http://animres.edpsciences.org/ index.php?option $=$ com_article $\&$ access $=$ doi $\&$ doi $=10.1051 /$ animres:2002028\&Itemid=129>. Acesso em: 02 jul. 2007. doi: 10.1051/animres: 2002028.

ROSTAGNO, H.S. et al. Tabelas brasileiras para aves e suínos; composição de alimentos e exigências nutricionais. Viçosa: Universidade Federal de Viçosa, 2005. $1 \mathrm{p}$.

SAS. Statistical analysis system Institute. Ed. 6.12. Cary, 1998. CD-Room.

SAS Institute Inc. SAS/STAT. User's guide, version 6.11, 4.ed. Cary, 2003. V.2.

WEDEKIND, K.J. et al. Bioavailability of zinc from inorganic and organic sources for pigs fed corn-soybean meal diets. Journal of Animal Science, v.72, n.10, p.2681-2689, 1994. Disponível em: <http://jas.fass.org/cgi/reprint/72/10/2681〉. Acesso em: 04 dez. 2006. 